\title{
Dietary responses of Sahul (Pleistocene Australia-New Guinea) megafauna to climate and environmental change
}

\author{
Larisa R. G. DeSantis, Judith H. Field, Stephen Wroe and John R. Dodson
}

\begin{abstract}
Throughout the late Quaternary, the Sahul (Pleistocene Australia-New Guinea) vertebrate fauna was dominated by a diversity of large mammals, birds, and reptiles, commonly referred to as megafauna. Since ca. 450-400 Ka, approximately 88 species disappeared in Sahul, including kangaroos exceeding $200 \mathrm{~kg}$ in size, wombat-like animals the size of hippopotamuses, flightless birds, and giant monitor lizards that were likely venomous. Ongoing debates over the primary cause of these extinctions have typically favored climate change or human activities. Improving our understanding of the population biology of extinct megafauna as more refined paleoenvironmental data sets become available will assist in identifying their potential vulnerabilities. Here, we apply a multiproxy approach to analyze fossil teeth from deposits dated to the middle and late Pleistocene at Cuddie Springs in southeastern Australia, assessing relative aridity via oxygen isotopes as well as vegetation and megafaunal diets using both carbon isotopes and dental microwear texture analyses. We report that the Cuddie Springs middle Pleistocene fauna was largely dominated by browsers, including consumers of $C_{4}$ shrubs, but that by late Pleistocene times the $\mathrm{C}_{4}$ dietary component was markedly reduced. Our results suggest dietary restriction in more arid conditions. These dietary shifts are consistent with other independently derived isotopic data from eggshells and wombat teeth that also suggest a reduction in $\mathrm{C}_{4}$ vegetation after $\sim 45 \mathrm{Ka}$ in southeastern Australia, coincident with increasing aridification through the middle to late Pleistocene. Understanding the ecology of extinct species is important in clarifying the primary drivers of faunal extinction in Sahul. The results presented here highlight the potential impacts of aridification on marsupial megafauna. The trend to increasingly arid conditions through the middle to late Pleistocene (as identified in other paleoenvironmental records and now also observed, in part, in the Cuddie Springs sequence) may have stressed the most vulnerable animals, perhaps accelerating the decline of late Pleistocene megafauna in Australia.
\end{abstract}

Larisa R. G. DeSantis. Department of Earth and Environmental Sciences, Vanderbilt University, Nashville, TN 37235-1805, U.S.A. E-mail: larisa.desantis@vanderbilt.edu

Judith H. Field. School of Biological, Earth and Environmental Sciences, University of New South Wales, Sydney, NSW 2052, Australia

Stephen Wroe. School of Biological, Earth and Environmental Sciences, University of New South Wales, Sydney, NSW 2052, Australia, and Department of Zoology, School of Environmental and Rural Sciences, University of New England, Armidale, NSW 2351, Australia

John R. Dodson. School of Biological, Earth and Environmental Sciences, University of New South Wales, Sydney, NSW 2052, Australia, and Institute of Earth Environment, Chinese Academy of Sciences, Xi'an, Shaanxi, 710061, China

Accepted: 2 November 2016

Published online: 26 January 2017

Data available from the Dryad Digital Repository: https://doi.org/10.5061/dryad.1s3d4

\section{Introduction}

Many of the world's largest terrestrial mammals disappeared during the late Quaternary (Roberts et al. 2001; Wroe and Field 2006; Barnosky et al. 2004; Grayson 2007; Wroe et al. 2013). In Sahul, 14 mammalian genera, approximately 88 species, and all taxa $>100 \mathrm{~kg}$ went extinct sometime between middle and late Pleistocene times (Wroe et al. 2013). Proportionally, Sahul (Pleistocene AustraliaNew Guinea) suffered the greatest loss of megafauna compared with other continents (Wroe et al. 2013). Long-running debates about cause and effect in the extinction process have produced no clear consensus on primary causative factors and suffer from the fact that relatively little is known about the ecology of 
most extinct species. Current explanatory narratives include overhunting (e.g., Roberts et al. 2001; Prideaux et al. 2009; Saltré et al. 2016), indirect effects of landscape modification (e.g., fire-stick farming by aboriginal people; Miller et al. 2005), and impacts of long-term climate change (Price and Webb 2006; Wroe and Field 2006; Faith and O'Connell 2011; Price et al. 2011; Wroe et al. 2013; Dortch et al. 2016). Any new information about the dietary habits of the Pleistocene fauna may improve understanding of their potential vulnerabilities to adverse climatic conditions and may clarify habitat preferences of these extinct taxa.

There have been few opportunities to study the ecology of megafauna taxa, as many species are represented by only a few elements and sometimes are known from only one or two localities (see Prideaux et al. 2007). One exception is the giant short-faced kangaroo Procoptodon. Using similar methods to those implemented here, the 2- to 3-m-tall Procoptodon was identified as a $\mathrm{C}_{4}$ browser of Atriplex (saltbush), apparently preferring the "tough chenopod leaves and stems," while also requiring access to free water (Prideaux et al. 2009).

Isotopic data and dental microwear studies can be useful indicators of mammalian diets at different times in the mid-late Pleistocene. Insights into dietary preferences as revealed in these studies will assist in helping to understand the potential impacts of climate and environmental change on individual species, particularly the vulnerability of large herbivores to long-term climatic deterioration. We know of no well-dated faunal sequences during the late Pleistocene on mainland Australia, apart from Cuddie Springs, that have an in situ paleoenvironmental record documenting local vegetation and thus enable a direct correlation of environmental setting with the dietary habits of now extinct fauna. In this study, geochemical and dental microwear texture analyses (DMTA) were integrated to assess the environmental setting and dietary ecology of mammalian megafaunal communities from two concentrated, fossil bone horizons at Cuddie Springs: one from the middle Pleistocene dated to between $~ 570$ $350 \mathrm{Ka}$, and the second from a period when megafauna were in decline, $\sim 40-30 \mathrm{Ka}$ (see Field et al. 2013).

\section{Site Setting and Paleoenvironmental History}

Present-day Cuddie Springs is located in southeastern Australia on the semiarid riverine plains of northwestern New South Wales (Field and Dodson 1999). It is an ancient ephemeral lake in a landscape of low relief and has been a low-energy depositional environment for hundreds of millennia. A treeless pan near the center of the lake fills after local rainfall and can take months to dry. Since the lake formed, the local environment has been primarily dominated by chenopod shrubland with scattered trees (Field et al. 2002). However, in the lead-up to the last glacial maximum (LGM, marine isotope stage 3), there was a shift to grasslands before the re-establishment of chenopod shrublands post-LGM (Field et al. 2002).

Cuddie Springs has been the subject of archaeological and prearchaeological excavations for more than two decades (Dodson et al. 1993; Field et al. 2013). A stratified sequence of lacustrine clays and silts encloses a faunal record that could extend to nearly $1 \mathrm{Myr}$ (Field and Dodson 1999; Grün et al. 2010). At approximately $2 \mathrm{~m}$ below the ground surface, there is a discrete concentration of megafaunal bone approximately $20 \mathrm{~cm}$ deep (stratigraphic unit 9 [SU9]; Supplementary Fig. 1; Field and Dodson 1999; Trueman et al. 2005; Field and Wroe 2012). A number of isolated tooth samples $(n=5)$ from SU9 were analyzed using ESR/U-series and returned ages between $569 \pm 80 \mathrm{Ka}$ and $347 \pm 55 \mathrm{Ka}$ (Grün et al. 2010; sample numbers include 2028, 2055, 2058-60; note: these samples were incorrectly noted as occurring during SU8B in Grün et al. 2010). Grün et al. (2010) present the age of SU9 as a weighted average mean of ca. $400 \mathrm{Ka}$, but omit why the dates were averaged in this way (note: we do list the average date in relevant tables and figures). The broad age range noted above encompasses three glacial cycles. The range of electron spin resonance (ESR)/U-series ages reflects the uncertainties in the dating method. In contrast to the wide age ranges resulting from ESR/U-series, geomorphological, geochemical, and taphonomic studies instead 
indicate that the bones in SU9 were deposited over a relatively short time period, possibly tens or hundreds of years rather than thousands (Field et al. 2001, 2008, 2013). The bones in SU9 accumulated in a low-energy environment, as indicated by the fine-grained lacustrine sediments, the articulated and separated articulated skeletal elements, and the pollen data (Field et al. 2008; and discussed below). An analysis of the faunal assemblage established that the bones were not weathered or abraded, and the rare earth elements (REE) study also indicated internal consistency (Trueman et al. 2005). Notably, many of the elements from SU9 displayed damage by crocodiles, and more than 200 isolated crocodile teeth (predominantly Pallimnarchus sp.) were identified (J. H. Field and J. Garvey, unpublished data).

Two pollen samples were analyzed from the SU9 unit. Pollen preparations were carried out in the clean pollen preparation laboratory in the Institute of Earth Environment in Xi'an, China. The abundance of pollen and spores differed a little between the samples, but both samples were dominated by Chenopodeaceae (53-67\%), with Poaceae (19 and 5\%), Asteraceae (about 6\%), and Casuarina (12-13\%) also present. Many other taxa were represented in small amounts $(<2-5 \%)$. These pollen data indicate that at the time of formation of SU9, the local environment was a saltbush plain with grasses, herbs, and scattered trees. The Casuarina component was probably from the immediate lake surrounds, growing adjacent to the ephemeral waterhole. Cyperaceae and aquatic taxa abundances were calculated outside the pollen sum. Cyperaceae were abundant at $19-36 \%$, along with Myriophyllum (25 and 5\%); both these taxa grow in still or slow-moving water bodies. Azolla spores (a small floating freshwater fern that grows in still, shallow freshwater; $>50 \%$ ) with abundant Azolla glochidia were also present. These pollen spores are consistent with a marshy environment and perhaps with periodic standing water, conditions not dissimilar from those found in the SU6B sequence.

Two sequential stratigraphic units (SU6A, SU6B; Supplementary Fig. 1), between ca. 1.7$1.05 \mathrm{~m}$ depth, contain discrete accumulations of artifactual stone interleaved with bone of extant and extinct species (Field and Dodson 1999; Fillios et al. 2010). SU6 was dated using ESR, optically stimulated luminescence (OSL), and radiocarbon techniques, with ages of $>40$ $\mathrm{Ka}$ to $\sim 30 \mathrm{Ka}$ (Field et al. 2001, 2013; Trueman et al. 2005; Grün et al. 2010). The sediments in SU6B consist of silts and clays, with ped formation and fine plant roots throughout, consistent with the geomorphological interpretation as a swamp. As such, the fine plant roots are likely to be the same age as the deposit. SU6B was formed during waterlogged conditions, either as a shallow, still water body or as a marshy deposit (Field et al. 2002). The faunal remains show little to no weathering, with no evidence of abrasion; are extremely fragile; and are mostly complete, with some elements preserved in anatomical order, for example, a Diprotodon optatum mandible and numerous postcranial elements of Genyornis newtoni (Wroe et al. 2004; Fillios et al. 2010; Field et al. 2013).

The Cuddie Springs investigations have been widely published with detailed descriptions of the in situ fossils and artifacts (as described earlier), yet the integrity of the site has been questioned on the basis of the OSL and ESR analyses (Roberts et al. 2001; Grün et al. 2010; Supplementary Fig. 1; but see Field 2006; Field et al. 2008, 2013). The ESR analyses for SU6 (Grün et al. 2010) produced, in some cases, ages that were considerably older than those produced with the OSL or radiocarbon analyses (also see Field et al. 2001). The Roberts et al. (2001) OSL study identified multiple age populations from the single-grain analysis (but see Field and Fullagar 2001; Field et al. 2008, 2013). Stratigraphic disturbance was forwarded as the most likely explanation by these authors, yet other studies of single-grain OSL dating have routinely identified multiple age populations, and the interpretation of disturbance invoked by Roberts et al. (2001) is rarely if ever interpreted this way (see Boulter et al. 2006; Cosgrove et al. 2010). Gillespie and Brook (2006: p. 9) also assert that the bones from Cuddie Springs (SU6) are "fossil rather than archaeological," inferring that bones and stone tools were not contemporaneous. These interpretations ignore the published results of 
systematic stratigraphic studies undertaken over two decades (e.g., Field and Dodson 1999; Field et al. 2001, 2008, 2013). Importantly, for the scenarios proposed by Grun et al. (2010) and Gillespie and Brook (2006) to have any credibility, the REE work of Trueman et al. (2005) had to be discredited. Grün et al. (2010: p. 608) then concluded that Trueman et al. (2005) were analyzing "surface coatings and/or detrital material contained in cracks and pores."

Trueman et al. (2005) were explicit in the description of their methodology and their approach, the salient points being: (1) the outer layers of bone were removed before sampling;

(2) REEs have a strong affinity for apatite; and (3) bones with the highest U:Th ratios had the lowest REE content, demonstrating that REEs were associated with apatite (see discussion in Field et al. [2013: p. 84]). Grün et al. (2010) also constructed a scenario in which bone, stone, and charcoal were deposited at different times, the bones being "transported laterally" to this location by an unspecified mechanism from an unidentified source. Furthermore, these authors suggested that there was a "basin" formed at the lake center, with the larger lake floor at or near present-day levels. Grün et al. (2010) further argue that these different levels produce an incline down which the bones would move, presumably for both SU6 and SU9. Gillespie and Brook (2006: p. 9) constructed another scenario, in which the animals, archaeology, and charcoal all accumulated by different mechanisms: "macro charcoal was transported to the site and later redeposited by floods.... European cattle farming significantly disturbed the claypan deposits." Significantly, there is no empirical evidence supporting any of these assertions. Gillespie and Brook (2006) also try to reconcile the REE data (Trueman et al. 2005) by suggesting that the local fauna died elsewhere, thus suggesting that all of the faunal remains were transported some distance in one episode. The various site formation processes forwarded by these authors require massive reworking and a demonstration of major landscape remodeling (not given) and notably have no support in the taphonomic, geomorphological, or archaeological studies undertaken to date (e.g., Trueman et al. 2005; Fillios et al. 2010; Field et al. 2001,
2008, 2013). For these reasons we reject the proposal that the site has been reworked, largely because there is no evidence to support this contention, while there is a significant amount of data contradicting these claims (e.g., Trueman et al. 2005; Fillios et al. 2010; Field et al. 2001, 2008, 2013).

Notably, the relative dating methods (ESR and OSL) used at Cuddie Springs have been applied to other Sahul sites-in particular Lake Mungo, NSW, and Devil's Lair in Western Australia-with interpretations in direct contrast to Cuddie Springs (Thorne et al. 1999; Turney et al. 2001). The ESR estimates in these cases were thousands of years older than those obtained by other methods, just like Cuddie Springs, but the ESR dates were subsequently excluded from consideration at those sites (e.g., Bowler et al. 2003). We would argue, then, that for Grün et al (2010) to maintain that the ESR dates are more reliable than the consensus of dates using other methods (OSL, ${ }^{14} \mathrm{C}$ ) at Cuddie Springs, they would need to demonstrate that their methods are not subject to the same sort of systematic error observed elsewhere. Similar conclusions were drawn from an OSL study undertaken by Roberts and colleagues (2001) at Cuddie Springs, in which multiple age populations were identified in the single-grain OSL data, and the authors subsequently concluded the site to have significant sediment disturbance. A similar pattern of multiple age populations was determined for a Tasmanian study of megafauna (Turney et al. [2008] and discussion in Cosgrove et al. [2010: p. 2497]); however, some of these age populations were "omitted for clarity," and an age of $\sim 45 \mathrm{Ka}$ was used instead. While further work is needed to better standardize the treatment of OSL data, there is still much that can be learned from the sites mentioned earlier. For this reason we continue to study megafauna and their paleoecology based on data at hand and the accumulated wealth of published information about the Cuddie Springs site.

\section{Paleoecological Proxies}

The Sahul megafauna suite included a diversity of marsupials, whose potential diet 
may have included $C_{3}$ and $C_{4}$ grasses and $\mathrm{C}_{3}$ and $\mathrm{C}_{4}$ trees/shrubs. Carbon isotope studies of fossil fauna can help identify the isotopic signatures of these dietary food sources (e.g., Cerling et al. 1997; Prideaux et al. 2009). When combined with dental microwear analyses (e.g., Prideaux et al. 2009), this approach can clarify long-term dietary trends in regions that contain a mixture of floral resources. The multiproxy approach implemented here provides a robust framework to clarify the dietary behavior of mammals. It is important to note that these proxy methods record diet during different times in an animal's life. Stable isotopes record diet and climate via carbon and oxygen isotopes, respectively, during the time of mineralization (e.g., Cerling et al. 1997; Passey and Cerling 2002), while dental microwear records diet over the past few days to weeks of an animal's life (e.g., Grine 1986). Here, we implemented these methods to investigate the dietary ecology of the mid- and late Pleistocene marsupial megafauna from Cuddie Springs.

Carbon isotope values from the tooth enamel of medium- to large-sized herbivorous marsupials can reflect food sources (i.e., modern plant values) when accounting for an enrichment factor of $\sim 13.0 \%$ (Prideaux et al. 2009) plus an additional $\sim 1.5 \%$ due to increased atmospheric $\mathrm{CO}_{2}$ (fossil fuel burning over the past two centuries; Friedli et al. 1986; Marino et al. 1992; Cerling et al. 1997). Thus, $\delta^{13} \mathrm{C}$ enamel values $\leq-9 \%$ reflect a predominantly $\mathrm{C}_{3}$ diet, whereas values $\geq-3 \%$ indicate a predominantly $\mathrm{C}_{4}$ diet. Further, more negative $\delta^{13} \mathrm{C}$ values can also suggest consumption of $C_{3}$ vegetation within denser forests than more positive $\delta^{13} \mathrm{C}$ values (van der Merwe and Medina 1989; Cerling et al. 2004; DeSantis and Wallace 2008; DeSantis 2011). Variation in stable isotope values within individual teeth have the potential to reveal seasonal differences in diet via carbon isotopes and changes in temperature, and/or precipitation/humidity via oxygen isotopes, respectively (e.g., Fraser et al. 2008; Brookman and Ambrose 2012). Additionally, oxygen isotope values from modern Macropus tooth enamel are highly correlated with relative humidity and precipitation, ideally suited for tracking changes in aridity over time (Murphy et al. 2007; Prideaux et al. 2007; Burgess and DeSantis 2013).

An important adjunct to isotope studies is DMTA, specifically the three-dimensional study of microwear textures resulting from the processing of food. Dental microwear attributes such as complexity and anisotropy (see "Materials and Methods") can distinguish extant grazers from browsers (e.g., Ungar et al. 2007; Prideaux et al. 2009; Scott 2012), allowing for dietary behavior to be revealed beyond geochemical designations. This semiautomated method quantifies surface features in three dimensions using scale-sensitive fractal analysis, a major advance over prior microwear methods that instead required human observers to count pits and scratches from twodimensional images, and subsequently minimizes observer biases (Ungar et al. 2003; Scott et al. 2005; DeSantis et al. 2013).

\section{Materials and Methods}

\section{Stable Isotope Analyses}

Geochemical bulk $(n=83)$ and serial samples $(n=89)$ of tooth enamel were extracted from systematically excavated faunal material from Cuddie Springs, housed in the publicly accessible collections of the Australian Museum (see Supplementary Tables 1 and 5 for all specimen numbers and associated data). All sampled teeth were drilled with a low-speed dental-style drill and carbide dental burrs ( $<1 \mathrm{~mm}$ burr width). Bulk samples were taken parallel to the growth axis of the tooth, while serial samples were taken perpendicular to the growth axis. Enamel powder was pretreated with $30 \%$ hydrogen peroxide for $24 \mathrm{~h}$ and $0.1 \mathrm{~N}$ acetic acid for $12 \mathrm{~h}$ to remove organics and secondary carbonates, respectively (Koch et al. 1997; DeSantis et al. 2009). These samples ( 1 mg per sample) were then run on a VG Prism stable isotope ratio mass spectrometer with an in-line ISOCARB automatic sampler in the Department of Geological Sciences at the University of Florida. The analytical precision is $\pm 0.1 \%$ o, based on replicate analyses of samples and standards (NBS 19). Stable isotope data were normalized to NBS 19 
and are reported in conventional delta $(\delta)$ notation for carbon $\left(\delta^{13} \mathrm{C}\right)$ and oxygen $\left(\delta^{18} \mathrm{O}\right)$, where $\delta^{13} \mathrm{C}$ (parts per mil, \%o $)=\left[\left(R_{\text {sample }} /\right.\right.$ $\left.\left.R_{\text {standard }}\right)-1\right]^{*} 1000$, and $R={ }^{13} \mathrm{C} /{ }^{12} \mathrm{C}$; and, $\delta^{18} \mathrm{O}$ (parts per mil, \%o $)=\left[\left(R_{\text {sample }} / R_{\text {standard }}\right)-1\right]^{*}$ 1000 , and $R={ }^{18} \mathrm{O} /{ }^{16} \mathrm{O}$; and the standard is VPDB (Pee Dee Belemnite, Vienna Convention; Coplen 1994). All stable isotopes (carbon and oxygen) are from the carbonate portion of tooth enamel hydroxylapatite.

\section{Dental Microwear Texture Analyses}

Dental microwear replicas of all extant and fossil taxa $(n=90)$ were prepared by molding and casting using polyvinylsiloxane dental impression material and Epotek 301 epoxy resin and hardener, respectively. Modern faunal specimens were examined in publicly accessible collections housed in the Australian Museum, Museum Victoria, and the Western Australian Museum (see Supplementary Table 13 for all specimen numbers and associated data). DMTA using white-light confocal profilometry and scale-sensitive fractal analysis (SSFA), was performed on all replicas of bilophodont teeth that preserved antemortem microwear, similar to prior work (Ungar et al. 2003, 2007; Scott et al. 2005; Prideaux et al. 2009; Scott 2012; DeSantis et al. 2012, 2013; Haupt et al. 2013; Donohue et al. 2013; DeSantis and Haupt 2014). Vombatids were not included in DMTA, because their tooth morphology is not analogous to the extant and extinct marsupials here examined.

All specimens were scanned in three dimensions in four adjacent fields of view for a total sampled area of $204 \times 276 \mu \mathrm{m}^{2}$. All scans were analyzed using SSFA software (ToothFrax and SFrax, Surfract Corporation, www.surfrait.com) to characterize tooth surfaces according to the variables of complexity $(A s f c)$ and anisotropy (epLsar). Complexity is the change in surface roughness with scale and is used to distinguish taxa that consume hard, brittle foods from those that eat softer/tougher ones (Ungar et al. 2003, 2007; Scott et al. 2005; Prideaux et al. 2009; Scott 2012; DeSantis et al. 2012, 2013; Haupt et al. 2013; Donohue et al. 2013; DeSantis and Haupt 2014; DeSantis 2016). Anisotropy is the degree to which surfaces show a preferred orientation, such as the dominance of parallel striations having more anisotropic surfaces-as is typical in grazers and consumers of tougher food items (Ungar et al. 2003, 2007; Prideaux et al. 2009; Scott 2012; DeSantis et al. 2013; DeSantis 2016).

\section{Statistical Analyses}

All statistical analyses follow the same methods of a priori geochemical and DMTA analysis (Ungar et al. 2003; DeSantis et al. 2009, 2013; Prideaux et al. 2009). Specifically, all carbon and oxygen isotope values within the same locality were analyzed using analysis of variance and post hoc Fisher's least significant difference (LSD) and Tukey's honest significant difference multiple comparisons, as all relevant samples from taxa with adequate sample sizes had $\delta^{13} \mathrm{C}$ values that were normally distributed and of equal variance (Shapiro-Wilk and Levene's tests, respectively). When like genera between localities were being compared, $t$-tests were used if isotopic values were normally distributed and of equal variance (comparison of $\delta^{13} \mathrm{C}$ values from SU6 and SU9); however, nonparametric tests (Mann-Whitney $U$-tests) were used when comparing like genera with unequal variance (i.e., $\delta^{18} \mathrm{O}$ values of Macropus from Cuddie Springs SU6 and SU9). Further, we compared the $\delta^{18} \mathrm{O}$ values of Macropus from Cuddie Springs with modern Macropus specimens from different climatic regimes (i.e., low, moderate, high rainfall; Prideaux et al. 2007) using the Kruskal-Wallis test and Dunn's procedure for multiple comparisons (due to significant differences in variance between Macropus $\delta^{18} \mathrm{O}$ values, Levene's test). Serial samples of both $\delta^{13} \mathrm{C}$ and $\delta^{18} \mathrm{O}$ values were compared using two-tailed $t$-tests. Furthermore, we compared the variability of individuals present during each stratigraphic unit by quantifying the absolute difference between an individual serial sample and the mean value for the same isotope and tooth and then comparing those differences (as opposed to the isotopic values) between SU6 and SU9 using two-tailed $t$-tests. The comparison undertaken here allows for individual isotopic variability to be assessed while removing any 
confounding effects that could result from comparing teeth with disparate $\delta^{13} \mathrm{C}$ or $\delta^{18} \mathrm{O}$ values.

DMTA variables are not normally distributed (Shapiro-Wilk tests, $p<0.05$ for DMTA variables for certain taxa); therefore, we used nonparametric statistical tests (Kruskal-Wallis) to compare differences among all taxa. Further, we used Dunn's procedure (Dunn 1964) to conduct multiple comparisons (between extant and/or extinct taxa) absent of the Bonferroni correction. As the Bonferroni correction is meant to reduce the likelihood of false positives (type I errors) by taking into consideration the number of comparisons being made, it also increases the probability of false negatives (type II errors; Cabin and Mitchell 2000; Nakagawa 2004). Furthermore, we do not want the number of extant and/or extinct comparisons to affect statistical differences between taxa; thus, the Bonferroni correction is not appropriate for our comparisons.

\section{Results and Discussion}

\section{Oxygen Isotopes and Paleoclimate}

Macropus teeth are known to be ideal for examining changes in aridity, as bulk $\delta^{18} \mathrm{O}$ enamel values of modern specimens are highly correlated with relative humidity and precipitation (Murphy et al. 2007; Prideaux et al. 2007; Burgess and DeSantis 2013). Additionally, Macropus taxa living today acquire most of their water from vegetation (e.g., Dawson 1995; Nowak 1999; Dawson et al. 2004), consistent with other "evaporation-sensitive" taxa capable of tracking changes in water deficits (Levin et al. 2006). Macropus $\delta^{18} \mathrm{O}$ bulk values from all horizons examined at Cuddie Springs are consistent with Macropus values from low rainfall regimes (Prideaux et al. 2007; Fig. 1A).

SU9 was formed under less arid conditions than SU6, as inferred from lower $\delta^{18} \mathrm{O}$ mean values in Macropus ( $p=0.024$, Mann-Whitney $U$-test; Fig. 1A, Supplementary Tables 1 and 2). Stable oxygen isotope values for SU9 are also significantly greater than those for extant kangaroos from high rainfall regimes, but are indistinguishable from kangaroos found in either medium or low rainfall regimes (Dunn's procedure; Supplementary Tables 3 and 4).

Macropus $\delta^{18} \mathrm{O}$ values from SU6 are significantly greater than those for extant kangaroos from both high and medium rainfall regimes and only indistinguishable from kangaroos from low rainfall regimes (Dunn's procedure; Supplementary Tables 3 and 4). Oxygen isotope values of Macropus during SU6 are also more variable (with a significantly higher variance, $p<0.0001)$ than those from SU9. This high level of variability could result from a time-averaged accumulation of specimens, which included animals that died during normal and drought years-a situation often observed in modern times. For example, oxygen isotope data from extant quokkas (Setonix brachyurus) on Rottnest Island (an $\sim 19 \mathrm{~km}^{2}$ island located $\sim 20 \mathrm{~km}$ from Perth in Western Australia) during a period of a few years to decades (largely collected during the 1950s1960s) yielded a $\delta^{18} \mathrm{O}$ range of $5.1 \%$ (see Supplementary Fig. 2 and Supplementary Table 5). The high level of $\delta^{18} \mathrm{O}$ variability was the result of fluctuating weather events, including droughts, and was produced over decades, even though significant time averaging (e.g., millennia) was absent. Kangaroo specimens should also be local and are unlikely to be from disparate geographic regions with distinctly different climates. Modern kangaroo home ranges are fairly limited: $90 \%$ of the kangaroos with the largest known home range, Macropus rufus, had home ranges of less than $10 \mathrm{~km}^{2}$ and never exceed dispersal distances of more than $13 \mathrm{~km}$ (Priddel et al. 1988; Fisher and Owens 2000). Differences in mean oxygen isotope values $(2.3 \%)$ between SU6 and SU9 are significant $(p=0.024)$. Shifts of this magnitude are similar to those of mammals observed during the Paleocene-Eocene thermal maximum, a dramatic period of warming $\sim 55 \mathrm{Ma}$ (Secord et al. 2012). Significant differences have also been observed between Pleistocene glacial and interglacial periods in Florida, where camelids, deer, and peccaries (all taxa present at both sites with samples sizes $>5$ ) exhibited increased mean $\delta^{18} \mathrm{O}$ values of $\sim 2.4 \%$ (ranging from 1.8 to 2.9\%; DeSantis et al. 2009). For Cuddie Springs, SU6 formed during a period of enhanced aridity (ca. 41-27 Ka) and 

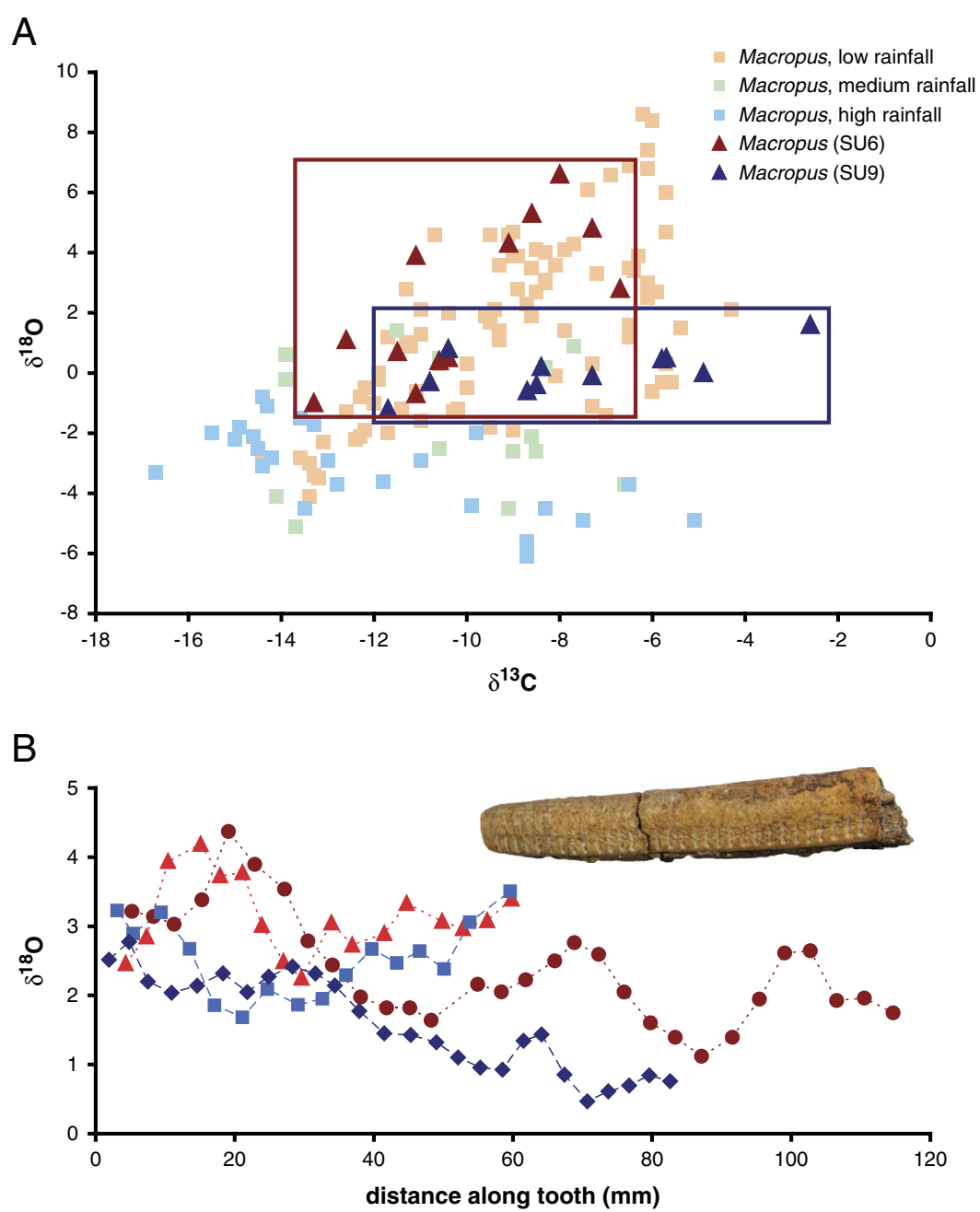

FIGURE 1. Stable isotope data indicative of relative aridity and seasonality. A, Stable carbon and oxygen isotope Macropus data of modern specimens from different rainfall regimes (Prideaux et al. 2007) and fossil specimens from Cuddie Springs. B, Serial oxygen isotope data of Diprotodon from individuals from prearchaeological (SU9, blue) and archaeological (SU6, red) horizons at Cuddie Springs shown with a serially sampled Diprotodon lower incisor.

contrasts with a less arid climatic regime during SU9 (ca. 570-350 Ka).

Oxygen isotope values from serially sampled incisors of the largest known marsupial ( 2700 kg) Diprotodon, indicate increased aridity and/or increased temperature during the formation of SU6, with significantly greater values at SU6 compared with SU9 (Fig. 1B, Supplementary Tables 6 and $7 ; p<0.0001$, twotailed $t$-test). Increased aridity is more likely, as Vostok and other Antarctic ice core records (Petit et al. 2001; Jouzel et al. 2007) indicate lower temperatures through SU6 relative to SU9 (Fig. 2A). Temperature and/or precipitation variability over the course of a year or more, as inferred from the amplitude of serial samples (assessed similar to Fraser et al. [2008] and Brookman and Ambrose [2012]), does not noticeably change between units. The absolute difference between a given serial sample and the mean value for a given tooth is similar between SU6 and SU9 (0.6 and 0.5, respectively; $p=0.941$ ).

Enamel $\delta^{18} \mathrm{O}$ values of teeth from SU6 and SU9 further support other data sets (e.g., REE; Trueman et al. 2005) that indicate an intact stratigraphic sequence at Cuddie Springs (Trueman et al. 2005; Fillios et al. 2010; Field et al. 2013). Specifically, $\delta^{18} \mathrm{O}$ bulk values of 
A

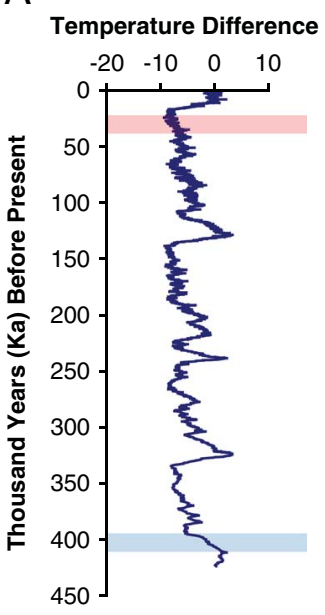

B

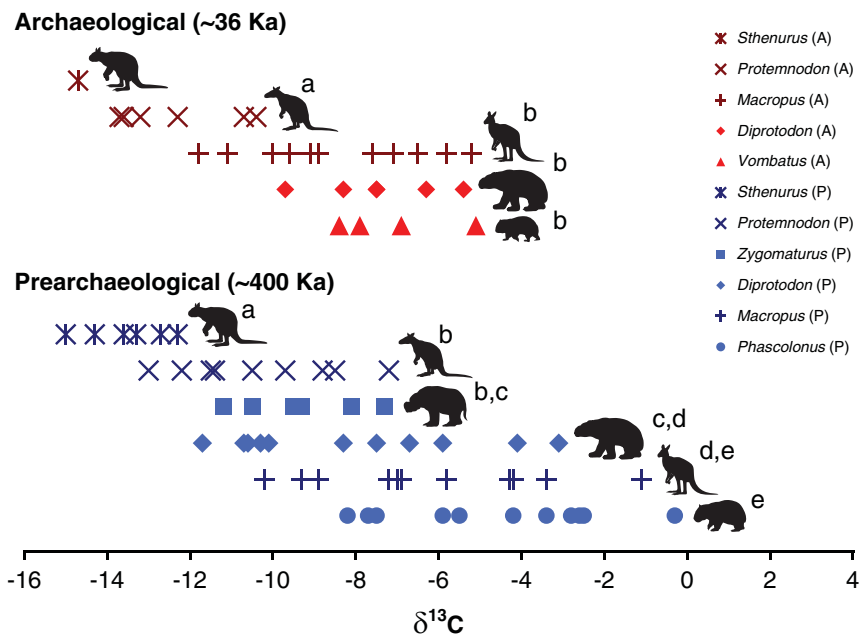

FiguRE 2. Geochemical data from the Vostok ice core (A) and the Cuddie Springs fauna (B). Vostok ice core data (Petit et al. 2001) with temperature differences based on $\delta^{18} \mathrm{O}$ values noted through time (A); blue and red highlighted areas correspond to prearchaeological and archaeological horizons at Cuddie Springs (Trueman et al. 2005; Fillios et al. 2010; Grün et al. 2010). Tooth enamel stable carbon isotope values for the Cuddie Springs fauna through time (B), prearchaeological (SU9, ESR dates, Grün et al. 2010; blue) and archaeological (SU6, calibrated radiocarbon dates, Fillios et al. 2010; red), carbon isotope values for individuals from corresponding temporal horizons are noted with distinct letters, indicating statistically different groups (i.e., taxa denoted with a $b$ are not distinct from one another but are distinct from taxa with $a, c, d$, and $e$ notation; Fisher's LSD, $p<0.05)$. P, prearchaeological; A, archaeological.

Macropus are significantly greater during SU6 compared with SU9-suggesting that these units are discrete-and are inconsistent with significant faunal mixing. Furthermore, the fairly narrow range of $\delta^{18} \mathrm{O}$ bulk values $(2.8 \%$ ) of Macropus at SU9 are in agreement with a fairly rapid period of deposition, as also inferred from geomorphological studies. This range is also lower than $\delta^{18} \mathrm{O}$ ranges that occur in extant kangaroos over a period of a few decades (as evinced by quokkas, mentioned earlier; Supplementary Fig. 2). Oxygen isotope data from SU6 mammalian enamel are consistent with paleoenvironmental evidence for marked drying at $\sim 50-45 \mathrm{Ka}$ (Bowler et al. 2003; Cohen et al. 2011) and, more broadly, longer-term climatic trends suggesting a trend of pronounced aridification since $\sim 450 \mathrm{Ka}$ (Nanson et al. 1992; Kershaw et al. 2003; Wroe et al. 2013).

\section{Carbon Isotopes and Dietary Niches}

During the formation of SU9 (ca. 570-350 Ka) the macropodids (Macropus, Protemnodon, and Sthenurus), diprotodontids (Diprotodon and Zygomaturus), and vombatid (Phascolonus) sampled in this study largely display disparate isotopic niches, with most taxa exhibiting significantly different mean $\delta^{13} \mathrm{C}$ values from other co-occurring mammals (Fig. 2B, Supplementary Tables 1,8 , and 9). Individual $\delta^{13} \mathrm{C}$ values range from -15 to $-0.3 \%$, indicating the presence of dense forest-dwelling $C_{3}$ consumers, mixed $\mathrm{C}_{3}$ and $\mathrm{C}_{4}$ consumers, and primarily $\mathrm{C}_{4}$ consumers. In contrast, megafauna from SU6 are largely indistinguishable from one another in $\delta^{13} \mathrm{C}$ values (Fig. 2B, Supplementary Tables 1,7 , and 10), with no individuals consuming primarily $\mathrm{C}_{4}$ resources (all individuals have $\delta^{13} \mathrm{C}$ values $\leq-5.1 \%$ ). As water-stressed $C_{3}$ plants can yield greater $\delta^{13} \mathrm{C}$ values with increased aridity (Tieszen 1991), the proportion of $\mathrm{C}_{4}$ resources consumed by marsupials occurring during the formation of SU6 may be overestimated here. Thus, the effects of aridity on diet and subsequent reduction of $\mathrm{C}_{4}$ plants consumed during SU6 compared with SU9 may be even more pronounced.

Stable carbon isotopes also reveal considerable differences in dietary niches among 
macropodids, diprotodontids, and vombatids. During the formation of SU9 (ca. 570-350 Ka), mean $\delta^{13} \mathrm{C}$ values of resident taxa ranged from $-13.5 \%$ in Sthenurus to $-4.6 \%$ in Phascolonus (Supplementary Table 8). The rank order of all taxa sampled, from the most depleted in ${ }^{13} \mathrm{C}$ (representing forest dwellers) to the most enriched in ${ }^{13} \mathrm{C}$ (indicating the consumption of vegetation in more open regions, including potentially $\mathrm{C}_{4}$ grasses and/or $\mathrm{C}_{4}$ shrubs such as saltbush) is, as follows: Sthenurus, Protemnodon, Zygomaturus, Diprotodon, Macropus, and Phascolonus (Supplementary Table 8).

Sthenurus has significantly lower $\delta^{13} \mathrm{C}$ values from all other taxa in SU9, while Protemnodon has significantly lower $\delta^{13} \mathrm{C}$ values than Diprotodon, Macropus, and Phascolonus (Supplementary Table 9). Similarly, Zygomaturus has significantly lower $\delta^{13} \mathrm{C}$ values than Macropus and Phascolonus, while Diprotodon has significantly lower $\delta^{13} \mathrm{C}$ values than Phascolonus (Supplementary Table 9). Interestingly, and in contrast to prior morphological work suggesting that Sthenurus species may have consumed xeromorphic shrubs and were more opencountry mixed feeders (Prideaux 2004), these isotopic data suggest that Sthenurus preferred the densest vegetation available (van der Merwe and Medina 1989), in agreement with carbon and nitrogen isotope analyses of bone collagen (Gröcke 1997). Specifically, Sthenurus consumed foliage in areas with denser canopies or understories than that consumed by other co-occurring macropods. While Protemnodon has greater $\delta^{13} \mathrm{C}$ values than Sthenurus, it had a preference for $\mathrm{C}_{3}$ browse, though was more of a mixed $\left(C_{3} / C_{4}\right)$ feeder than was Sthenurus. Macropus consumed the greatest proportion of $\mathrm{C}_{4}$ resources of all macropodids analyzed, suggesting it consumed a large portion of $\mathrm{C}_{4}$ grasses and/or $\mathrm{C}_{4}$ shrubs such as saltbush. Further, the rank order of $\delta^{13} \mathrm{C}$ values of all macropodids is maintained from SU9 to SU6 (although Sthenurus is only represented by one sample; Supplementary Table 8, Supplementary Fig. 3). In SU6 Protemnodon had a significantly lower mean $\delta^{13} \mathrm{C}$ value than Macropus, Diprotodon, and Vombatus. Nonetheless, all macropods with sample sizes appropriate for analysis demonstrate a significant decline in $\delta^{13} \mathrm{C}$ values with increased aridity $(p<0.05)$. Declining $\delta^{13} \mathrm{C}$ values are contrary to expectations, as increased aridity is likely to result in greater (i.e., water-stressed; Tieszen 1991) $\delta^{13} \mathrm{C}$ values and/or an increase of $\mathrm{C}_{4}$ vegetation on the landscape (as seen in DeSantis et al. 2009). Significant declines in $\delta^{13} \mathrm{C}$ values, coupled with aridity, suggest that macropods were shifting their diets to compensate for changing climatic conditions. If $\mathrm{C}_{4}$ vegetation was less palatable during more arid conditions (either due to lower water content and/or increased salt content in the case of $\mathrm{C}_{4}$ shrubs like Atriplex), herbivorous megafauna may have been competing for a reduced suite of vegetative resources during SU6.

Both diprotodontids at Cuddie Springs (i.e., Zygomaturus and Diprotodon in SU9) had $\delta^{13} \mathrm{C}$ values suggesting consumption of both $\mathrm{C}_{3}$ and $\mathrm{C}_{4}$ resources. Despite Zygomaturus having a smaller body size than Diprotodon (e.g., Murray 1991), isotopic data suggest they consumed similar dietary resources. The diet of Diprotodon at Cuddie Springs also varied seasonally; however, total $\delta^{13} \mathrm{C}$ variability per individual sampled is $\leq 3 \%$, indicating that Diprotodon did not switch from eating only $C_{3}$ vegetation to only $\mathrm{C}_{4}$ vegetation (which would result in larger individual $\delta^{13} \mathrm{C}$ variability than $3 \%$; Supplementary Fig. 4, Supplementary Tables 6 and 7). Instead, Diprotodon had a diet with more subtle annual or semiannual differences. Interestingly, variability in serial carbon isotope samples compared with the mean value for a given tooth is significantly greater during SU6 when compared with SU9 (0.7 and 0.5, respectively; $p=0.02)$. These data suggest that while mean $\delta^{13} \mathrm{C}$ bulk values of Diprotodon do not vary between stratigraphic units, individuals present during SU6 consumed more temporally variable diets than did individuals from SU9.

The vombatids Phascolonus (SU9) and Vombatus (SU6) consumed the greatest proportion of $\mathrm{C}_{4}$ resources of all Cuddie Springs taxa sampled. As extant members of the genus Vombatus consume primarily grasses (Nowak 1999; Triggs 2009), it is likely that the Cuddie Springs vombatids consumed $\mathrm{C}_{4}$ grasses during the formation of SU6 and SU9. 
Nonetheless, during SU6 Vombatus probably supplemented its diet with $C_{3}$ resources, as these data suggest that none of the marsupials sampled from SU6 were specialized $\mathrm{C}_{4}$ consumers. The small amount of $\mathrm{C}_{4}$ flora consumed by SU6 Vombatus at Cuddie Springs, as inferred from $\delta^{13} \mathrm{C}$ values $<-5.0 \%$, is consistent with the Miller et al. (2005) study, in which wombats (in addition to flightless birds) reduce their consumption of $\mathrm{C}_{4}$ vegetation during the late Pleistocene.

\section{Dental Microwear Texture Analysis and \\ Paleoecology}

Modern vegetation around Cuddie Springs consists of semiarid woodland with a shrub understory including chenopods, grasses, and lignum (Field et al. 2002). As many chenopods are $\mathrm{C}_{4}$ plants, including the saltbush Atriplex, we cannot discern from isotopes alone whether the decline in $\mathrm{C}_{4}$ consumption reflects declining grass or saltbush consumption, though the pollen record for this period (SU6) does reflect a local shift to grasses from saltbush (Field et al. 2002). DMTA can distinguish between extant grazing and browsing macropods (Prideaux et al. 2009) and in this study revealed differences between extant grazers (Macropus giganteus), grazers with a more varied diet (Macropus fuliginosus), browsers (Setonix brachyurus), and browsers with a more varied diet (Wallabia bicolor; Fig. 3; Arman and Prideaux 2015). All identified fossil macropodid and diprotodontid taxa from Cuddie Springs (Macropus, Protemnodon, Sthenurus, Diprotodon, Palorchestes, Zygomaturus) yielded dental microwear textures indicative of browsing
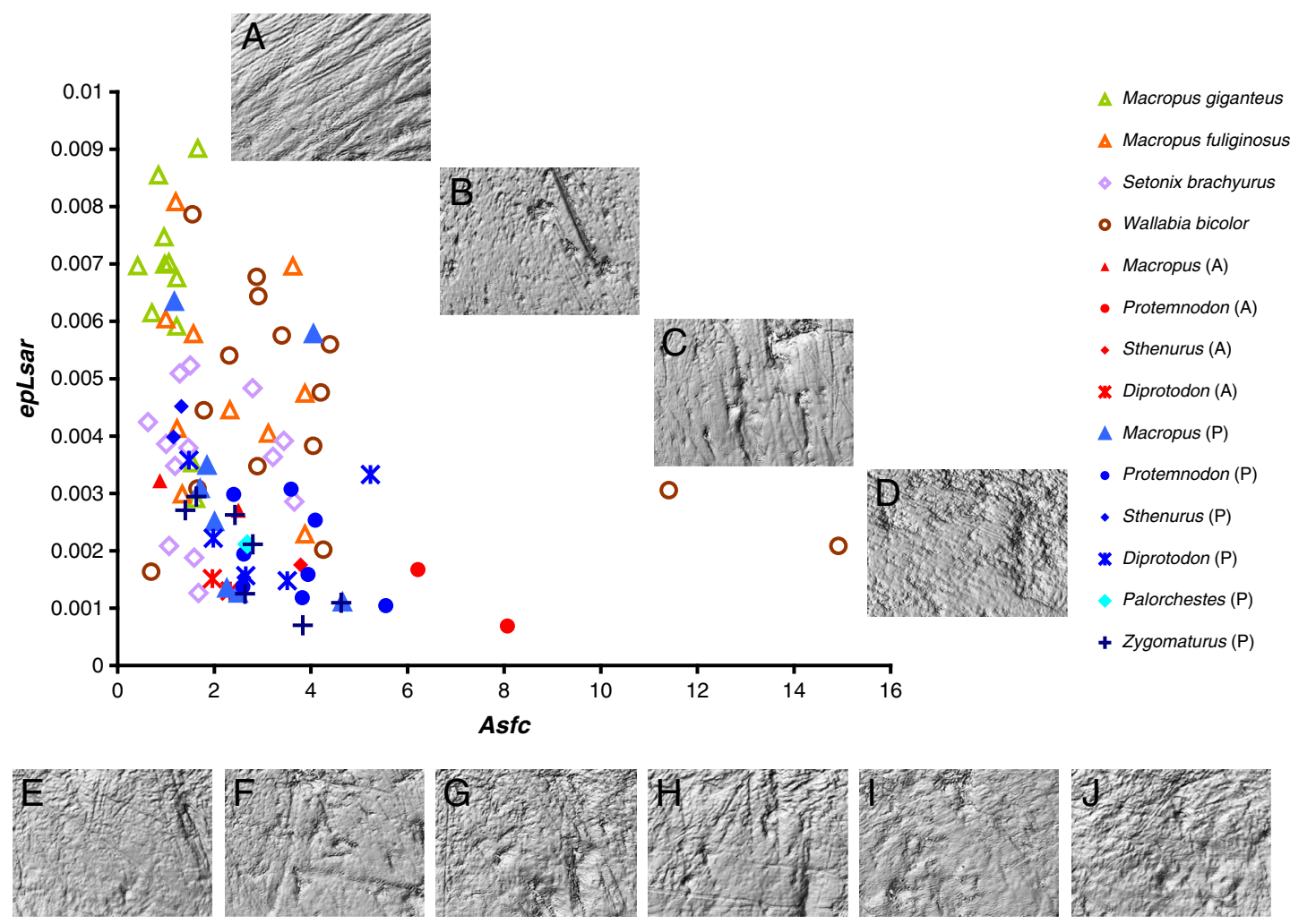

FIGURE 3. DMTA values and photosimulations for extant (A-D) and extinct taxa (E-J) from Cuddie Springs. A scatter plot of dental microwear texture attributes of complexity $(A s f c)$ and anisotropy (epLsar) of extant and extinct taxa. Extant taxa (open symbols, A-D); extinct taxa (solid symbols, E-J; P, prearchaeological; A, archaeological). Photosimulations of the following extant museum specimens are included: Macropus giganteus (A, MV-C24527), Macropus fuliginosus (B, WAM-M12229), Setonix brachyurus (C, WAM-M3543), and Wallabia bicolor (D, AM-M36793). Cuddie Springs photosimulations of prearchaeological (SU9) specimens include: Macropus (E, CS-1059), Protemnodon (F, CS-1069), Sthenurus (G, CS-1071), Palorchestes (H, CS-1049), Diprotodon (I, CS-1034), and Zygomaturus (J, CS-1044). 
(low anisotropy, epLsar; high complexity, Asfc; Fig. 3, Supplementary Tables 11-14). All samples (except Palorchestes, which was excluded from statistical analyses due to small sample size) were indistinguishable in complexity (indicative of harder object feeding) from the extant swamp wallaby (W. bicolor; $p>0.05)$. Further, these taxa are all significantly different $(p<0.05)$ in both $A s f c$ and epLsar from the extant obligate grazer Macropus giganteus.

In contrast to disparate mean $\delta^{13} \mathrm{C}$ values of macropodids from SU9 and SU6 (Supplementary Fig. 2), all macropodids consumed a significant portion of woody or more brittle floral material. However, Protemnodon consumed more brittle material than Macropus (Fig. 3, Supplementary Table 12), as suggested by greater complexity $(A s f c)$ values in the former. Furthermore, the Cuddie Springs Macropus are significantly different, in both complexity and anisotropy (epLsar), from the extant grazing kangaroo (Macropus giganteus; Supplementary Tables 12 and 13). Collectively, these data suggest that macropodids from Cuddie Springs consumed a broad range of floral resources and had disparate dietary niches. However, all macropodids likely consumed a greater amount of browse, including shrubs (e.g., saltbush, especially likely in taxa with elevated $\delta^{13} \mathrm{C}$ values and when considering the abundance of chenopods as supported by pollen data; Supplementary Figs. 5 and 6) than modern extant grazing kangaroos, as indicated by DMTA data (Fig. 3, Supplementary Tables 12-14).

\section{Concluding Remarks}

Collectively, DMTA data indicate that browsers dominated the Cuddie Springs fauna. Furthermore, $\mathrm{C}_{4}$ shrubs such as saltbush may have been a preferred component of the diet of some taxa, as has been suggested for the giant short-faced kangaroo, Procoptodon goliah (Prideaux et al. 2009). Importantly, our data demonstrate that these $C_{4}$ consumers were restricted to predominantly $\mathrm{C}_{3}$ resources in the late Pleistocene. The long-term aridification trend identified in other paleoenvironmental records (Nanson et al. 1992; Kershaw et al. 2003; Cohen et al. 2011; Wroe et al. 2013) may have reduced the availability of $C_{4}$ resources at the times these fossil records were formed. During a climatic downturn, the potential of megafauna to consume $\mathrm{C}_{4}$ resources such as saltbush may have also been reduced, because of the need to increase water intake to compensate for increased salt consumption (as demonstrated by Prideaux et al. 2009). If standing water and/or plant water were diminished at these times or competition (with crocodiles or other taxa) reduced access, saltbush (due to its high salt content) would become less palatable, thereby increasing competition for other plant resources.

Previous studies of $\mathrm{C}_{3}$ and $\mathrm{C}_{4}$ plant consumption, conducted on emu and Genyornis newtoni eggshell and mammalian tooth enamel (Miller et al. 2005), have demonstrated similar declines in $\mathrm{C}_{4}$ resource consumption. The subsequent vulnerability of the large flightless bird, Genyornis newtoni, to deteriorating climate from around $50 \mathrm{Ka}$ (Kershaw et al. 2003; Cohen et al. 2011) occurred during a period of very low human population densities across Sahul (Williams 2013). A time-series analysis of the same eggshell data (Murphy et al. 2012) determined that changes in emu diet are better correlated with fluctuating Lake Eyre water levels (Kershaw et al. 2003; Cohen et al. 2011). As such, this interpretation contrasts markedly with the initial conclusion that attributed Genyornis decline to ecosystem disruption by the landscape burning of colonizing humans (Miller et al. 2005), for which there is no empirical evidence for this region. Instead, data from Miller et al. (2005) as interpreted by Murphy et al. (2012) suggest that increased aridity may have been a driving factor influencing bird and wombat dietary shifts (a reduction in $\mathrm{C}_{4}$ consumption, like we see at Cuddie Springs) and perhaps their eventual extinction.

The reduction of $\mathrm{C}_{4}$ resources consumed by marsupial herbivores during the formation of SU6 suggests that megafauna may have been subject to increased competition for similar resources. It contrasts with SU9, when a broader range of palatable vegetative resources and suitable niches could be partitioned. It is 
also clear that megafauna living during SU6 experienced more arid conditions compared with those occurring during the formation of SU9. These data, together with published climatic data, lend support to a climatic downturn in the lead-up to the LGM (Nanson et al. 1992; Kershaw et al. 2003; Cohen et al. 2011; Wroe et al. 2013). The deteriorating climatic conditions that would have driven significant environmental reconfiguration during MIS3 may have strongly impacted the megafauna suite that persisted during the late Pleistocene in arid southeastern Sahul.

\section{Acknowledgments}

This work was supported by the National Science Foundation (EAR1053839 and FAIN1455198), the Australian Research Council (ARC LP211430 and DP05579230), the University of New South Wales, the University of Sydney, Oak Ridge Associated Universities Ralph E. Powe Junior Faculty Enhancement Award, and Vanderbilt University (including the Discovery Grant Program). We thank M. Fillios, J. Garvey, R. How, S. Ingleby, W. Longmore, K. Privat, K. Roberts, and C. Stevenson for contributions to the study and/or access to materials. Enormous gratitude is due to P. Ungar and J. Scott for initial access to and assistance with DMTA; J. Curtis for isotopic analysis; J. Olsson for the shadow drawings in Fig. 2B; and J. Roe for the Cuddie Springs map and section drawings. We are beholden to the Brewarrina Aboriginal Community; the Walgett Shire Council; the Johnstone, Currey, and Green families; and many volunteers for their support and assistance in the research at Cuddie Springs. Many thanks to Douglas and Barbara Green for facilitating access to the site. Thanks to I. Davidson, D. Fox, S. Mooney, R. Secord, and anonymous reviewers for comments on an earlier version of this article.

\section{Literature Cited}

Arman, S. D., and G. J. Prideaux. 2015. Dietary classification of extant kangaroos and their relatives (Marsupialia: Macropodoidea). Austral Ecology 40:909-922.

Barnosky, A. D., P. L. Koch, R. S. Feranec, S. L. Wing, and A. B. Shabel. 2004. Assessing the causes of Late Pleistocene extinctions on the continents. Science 306:70-75.
Bowler, J. M., H. Johnston, J. M. Olley, J. R. Prescott, R. G. Roberts, W. Shawcross, and N. A. Spooner. 2003. New ages for human occupation and climate change at Lake Mungo, Australia. Nature 421:837-840.

Boulter, C. H., M.D. Bateman, and A. S. Carr. 2006. Assessment of archaeological site integrity of sandy substrates using luminescence dating. Newsletter of the Society for Archaeological. Sciences 29(2), 8-12.

Brookman, T. A., and S. H. Ambrose. 2012. Seasonal variation in kangaroo tooth enamel oxygen and carbon isotopes in southern Australia. Quaternary Research 78:256-265.

Burgess, C. L., and L. R. G. DeSantis. 2013. Stable isotope ecology of the red-necked wallaby (Macropus rufogriseus): clarifying speciesspecific responses to climate and geographic variables. Young Scientist 3:1-4.

Cabin, R. J., and R. J. Mitchell. 2000. To Bonferroni or not to Bonferroni: when and how are the questions. Bulletin of the Ecological Society of America 81:246-248.

Cerling, T. E., J. M. Harris, B. J. MacFadden, M. G. Leakey, J. Quade, V. Eisenmann, and J. R. Ehleringer. 1997. Global vegetation change through the Miocene/Pliocene boundary. Nature 389:153-158.

Cerling, T. E., J. A. Hart, and T. B. Hart. 2004. Stable isotope ecology in the Ituri Forest. Oecologia 138:5-12.

Cohen, T. J., G. C. Nanson, J. D. Jansen, B. G. Jones, and Z. Jacobs. 2011. Continental aridification and the vanishing of Australia's megalakes. Geology 39:167-170.

Coplen, T. B. 1994. Reporting of stable hydrogen, carbon, and oxygen isotopic abundances. Pure and Applied Chemistry 66:273-276

Cosgrove, R., J. Field, J. Garvey, J. Brenner-Coltrain, A. Goede, B. Charles, S. Wroe, A. Pike-Tay, R. Grun, M. Aubert, W. Lees, and J. O'Connell. 2010. Overdone overkill-the archaeological perspective on Tasmanian megafaunal extinctions. Journal of Archaeological Science 37:2486-2503.

Dawson, T. J. 1995. Kangaroos: biology of the largest marsupials. Sydney: University of New South Wales Press.

Dawson, T. J., K. J. McTavish, and B. A. Ellis. 2004. Diets and foraging behaviour of red and eastern grey kangaroos in arid shrub land: is feeding behaviour involved in the range expansion of the eastern grey kangaroo in the arid zone? Australian Mammalogy 20:169-178.

DeSantis, L. G. 2011. Stable isotope ecology of extant tapirs from the Americas. Biotropica 43:746-754.

DeSantis, L. R. G. 2016. Dental microwear textures: reconstructing diets of fossil mammals. Surface Topography: Metrology and Properties 4(2), 023002.

DeSantis, L. R. G., and R. J. Haupt. 2014. Cougars' key to survival through the Late Pleistocene extinction: insights from dental microwear texture analysis. Biology Letters 10:20140203.

DeSantis, L. R., and S. C. Wallace. 2008. Neogene forests from the Appalachians of Tennessee, USA: geochemical evidence from fossil mammal teeth. Palaeogeography, Palaeoclimatology, Palaeoecology 266:59-68.

DeSantis, L. R. G., R. S. Feranec, and B. J. MacFadden. 2009. Effects of global warming on ancient mammalian communities and their environments. PLoS ONE 4:e5750.

DeSantis, L. R. G., B. W. Schubert, J. R. Scott, and P. S. Ungar. 2012. Implications of diet for the extinction of saber-toothed cats and American lions. PLoS ONE 7:e52453.

DeSantis, L. R. G., J. R. Scott, B. W. Schubert, S. L. Donohue, B. M. McCray, C. A. Van Stock, A. A. Wilburn, M. A. Greshko, and M. C. O'Hara. 2013. Direct comparison of 2D and 3D dental microwear proxies in extant herbivorous and carnivorous mammals. PLoS ONE 8:e71428.

Dodson, J. R., R. Fullagar, J. H. Furby, R. Jones, and I. P. Prosser. 1993. Humans and megafauna in a Late Pleistocene environment 
from Cuddie Springs, north western New South Wales. Archaeology in Oceania 28:94-99.

Donohue, S. L., L. R. G. DeSantis, B. W. Schubert, and P. S. Ungar. 2013. Was the giant short-faced bear a hyper-scavenger? A new approach to the dietary study of ursids using dental microwear textures. PLoS ONE 8:e77531.

Dortch, J., M. Cupper, R. Grun, B. Harpley, K. Lee, and J. Field. 2016. The timing and cause of megafauna mass deaths at Lancefield Swamp, south-eastern Australia. Quaternary Science Reviews 145:161-182.

Dunn, O. J. 1964. Multiple comparisons using rank sums. Technometrics 6:241-252.

Faith, J. T., and J. F. O'Connell. 2011. Revisiting the late Pleistocene mammal extinction record at Tight Entrance Cave, southwestern Australia. Quaternary Research 76:397-400.

Field, J. 2006. Trampling through the Pleistocene: Does taphonomy matter at Cuddie Springs? Australian Archaeology 63:9-20.

Field, J., and J. Dodson. 1999. Late Pleistocene megafauna and archaeology from Cuddie Springs, south-eastern Australia. Proceedings of the Prehistoric Society 65:275-301.

Field, J., and R. Fullagar. 2001. Archaeology and Australian megafauna. Science 294:7.

Field, J., and S. Wroe. 2012. Aridity, faunal adaptations and the Australian late Pleistocene faunal extinctions. World Archaeology 44(1), 56-74.

Field, J., R. Fullagar, and G. Lord. 2001. A large area archaeological excavation at Cuddie Springs. Antiquity 75:696-702.

Field, J. H., J. R. Dodson, and I. P. Prosser. 2002. A Late Pleistocene vegetation history from the Australian semi-arid zone. Quaternary Science Reviews 21:1023-1037.

Field, J., M. Fillios, and S. Wroe. 2008. Chronological overlap between humans and megafauna in Sahul (Pleistocene Australia-New Guinea): a review of the evidence. Earth Science Reviews 89:97-115.

Field, J., S. Wroe, C. N. Trueman, J. Garvey, and S. Wyatt-Spratt. 2013. Looking for the archaeological signature in Australian megafaunal extinctions. Quaternary International 285:76-88.

Fillios, M., J. Field, and B. Charles. 2010. Investigating human and megafauna co-occurrence in Australian prehistory: mode and causality in fossil accumulations at Cuddie Springs. Quaternary International 211:123-143.

Fisher, D. O., and I. P. Owens. 2000. Female home range size and the evolution of social organization in macropod marsupials. Journal of Animal Ecology 69:1083-1098.

Fraser, R. A., R. Grün, K. Privat, and M. K. Gagan. 2008. Stableisotope microprofiling of wombat tooth enamel records seasonal changes in vegetation and environmental conditions in eastern Australia. Palaeogeography, Palaeoclimatology, Palaeoecology 269:66-77.

Friedli, H., H. Lötscher, H. Oeschger, U. Siegenthaler, and B. Stauffer. 1986. Ice core record of the ${ }^{13} \mathrm{C} /{ }^{12} \mathrm{C}$ ratio of atmospheric $\mathrm{CO}_{2}$ in the past two centuries. Nature 324:237-238.

Gillespie, R., and B. W. Brook. 2006. Is there a Pleistocene archaeological site at Cuddie Springs? Archaeology in Oceania 41:1-11.

Grayson, D. K. 2007. Deciphering North American Pleistocene extinctions. Journal of Anthropological Research 63:185-214.

Grine, F. E. 1986. Dental evidence for dietary differences in Australopithecus and Paranthropus: a quantitative analysis of permanent molar microwear. Journal of Human Evolution 15:783-822.

Gröcke, D. R. 1997. Stable-isotope studies on the collagenic and hydroxylapatite components of fossils: palaeoecological implications. Lethaia 30:65-78.

Grün, R., S. Eggins, M. Aubert, N. Spooner, A.W.G. Pike, and W. Müller. 2010. ESR and U-series analysis of faunal material from Cuddie Springs, NSW, Australia: implications for the timing of the extinction of the Australian megafauna. Quaternary Science Reviews 29:596-610.
Haupt, R. J., L. R. G. DeSantis, J. L. Green, and P. S. Ungar. 2013. Dental microwear texture as a proxy for diet in xenarthrans. Journal of Mammalogy 94:856-866.

Jouzel, J., V. Masson-Delmotte, O. Cattani, G. Dreyfus, S. Falourd, G. Hoffman, B. Minster, K. Nouet, J. M. Barnola, J. Chappellaz, H. Fischer, J. C. Gallet, S. Johnsen, M. Leuenberger, L. Loulergue, D. Luethi, H. Oerter, F. Parrenin, G. Raisbeck, D. Raynaud, A. Schilt, J. Schwander, E. Selmo, R. Souchez, R. Spahni, B. Stauffer, J. P. Steffensen, B. Stenni, T. F. Stocker, J. L. Tison, M. Werner, and E. W. Wolff. 2007. Orbital and millennial Antarctic climate variability over the last 800,000 years. Science 317:793-796.

Kershaw, P., P. Moss, and S. van der Kaars. 2003. Causes and consequences of long-term climatic variability on the Australian continent. Freshwater Biology 48:1274-1283.

Koch, P. L., N. Tuross, and M. L. Fogel. 1997. The effects of sample treatment and diagenesis on the isotopic integrity of carbonate in biogenic hydroxylapatite. Journal of Archaeological Science 24:417-429.

Levin, N. E., T. E. Cerling, B. H. Passey, J. M. Harris, and J. R. Ehleringer. 2006. A stable isotope aridity index for terrestrial environments. Proceedings of the National Academy of Sciences USA 103:11201-11205.

Marino, B. D., M. B. McElroy, R. J. Salawitch, and W. G. Spaulding. 1992. Glacial-to-interglacial variations in the carbon isotopic composition of atmospheric $\mathrm{CO}_{2}$. Nature 357:461-466.

Miller, G. H., M. L. Fogel, J. W. Magee, M. K. Gagan, S. J. Clarke, and B. J. Johnson. 2005. Ecosystem collapse in Pleistocene Australia and a human role in megafaunal extinction. Science 309:287-290.

Murphy, B. P., D. M. J. S. Bowman, and M. K. Gagan. 2007. The interactive effect of temperature and humidity on the oxygen isotope composition of kangaroos. Functional Ecology 21: 757-766.

Murphy, B. P., G. J. Williamson, and D. M. J. S. Bowman. 2012. Did central Australian megafaunal extinction coincide with abrupt ecosystem collapse or gradual climate change? Global Ecology and Biogeography 21:142-151.

Murray, P. 1991. The Pleistocene megafauna of Australia. Pp. 1071-1164 in R. P. Vickers, J. M. Monaghan, R. F. Baird, and T. H. Rich, eds. Vertebrate palaeontology of Australasia. Victoria: Pioneer Design Studio.

Nakagawa, S. 2004. A farewell to Bonferroni: the problems of low statistical power and publication bias. Behavioral Ecology 15:1044-1045.

Nanson, G. C., D. M. Price, and S. A. Short. 1992. Wetting and drying of Australia over the past $300 \mathrm{ka}$. Geology 20: 791-794.

Nowak, R. M. 1999. Walker's mammals of the world, 6th ed. Baltimore, Md: Johns Hopkins University Press.

Passey, B. H., and T. E. Cerling. 2002. Tooth enamel mineralization in ungulates: implications for recovering a primary isotopic time-series. Geochimica et Cosmochimica Acta 66:3225-3234.

Petit, J. R., J. Jouzel, D. Raynaud, N. I. Barkov, J. M. Barnola, I. Basile, M. Bender, J. Chappellaz, J. Davis, G. Delaygue, M. Delmotte, V. M. Kotlyakov, M. Legrand, V. Lipenkov, C. Lorius, L. Pépin, C. Ritz, E. Saltzman, and M. Stievenard. 2001. Vostok Ice core data for 420,000 years. IGBP PAGES/World Data Center for Paleoclimatology Data Contribution Series \#2001-076. Boulder, Colo.: NOAA/NGDC Paleoclimatology Program. ftp://ftp.ncdc.noaa.gov/pub/data/paleo/icecore/antarctica/ vostok/deutnat.txt.

Price, G. J., and G. E. Webb. 2006. Late Pleistocene sedimentology, taphonomy and megafauna extinction on the Darling Downs, southeastern Queensland. Australian Journal of Earth Sciences 53:947-970. 
Price, G. J., G. E. Webb, J. Zhao, Y. Feng, A. S. Murray, B. N. Cooke, S. A. Hocknull, and I. H. Sobbe. 2011. Dating megafaunal extinction on the Pleistocene Darling Downs, eastern Australia: the promise and pitfalls of dating as a test of extinction hypotheses. Quaternary Science Reviews 30:899-914.

Priddel, D., G. Wellard, and N. Shepherd. 1988. Movements of sympatric red kangaroos, Macropus rufus, and western grey kangaroos, Macropus fuliginosus, in Western New-South-Wales. Wildlife Research 15:339-346.

Prideaux, G. 2004. Systematics and evolution of the sthenurine kangaroos. Berkeley: University of California Press.

Prideaux, G. J., J. A. Long, L. K. Ayliffe, J. C. Hellstrom, B. Pillans, W. E. Boles, M. N. Hutchinson, R. G. Roberts, M. L. Cupper, L. J. Arnold, P. D. Devine, and N. M. Warburton. 2007. An aridadapted middle Pleistocene vertebrate fauna from south-central Australia. Nature 445:422-425.

Prideaux, G. J., L. K. Ayliffe, L.R.G. DeSantis, B. W. Schubert, P. F. Murray, M. K. Gagan, and T. E. Cerling. 2009. Extinction implications of a chenopod browse diet for a giant Pleistocene kangaroo. Proceedings of the National Academy of Sciences USA 106:11646-11650.

Roberts, R. G., T. F. Flannery, L. K. Ayliffe, H. Yoshida, J. M. Olley, G. J. Prideaux, G. M. Laslett, A. Baynes, M. A. Smith, R. Jones, and B. L. Smith. 2001. New ages for the last Australian megafauna: continent-wide extinction about 46,000 years ago. Science 292:1888-1892.

Saltré, F., M. Rodríguez-Rey, B. W. Brook, C. N. Johnson, C. S. Turney, J. Alroy, A. Cooper, N. Beeton, M. I. Bird, D. A. Fordham, and R. Gillespie. 2016. Climate change not to blame for late Quaternary megafauna extinctions in Australia. Nature Communications 7:10511.

Scott, J. R. 2012. Dental microwear texture analysis of extant African Bovidae. Mammalia 76:157-174.

Scott, R. S., P. S. Ungar, T. S. Bergstrom, C. A. Brown, F. E. Grine, M. F. Teaford, and A. Walker. 2005. Dental microwear texture analysis shows within-species diet variability in fossil hominins. Nature 436:693-695.

Secord, R., J. I. Bloch, S. G. Chester, D. M. Boyer, A. R. Wood, S. L. Wing, M. J. Kraus, F. A. McInerney, and J. Krigbaum. 2012. Evolution of the earliest horses driven by climate change in the Paleocene-Eocene thermal maximum. Science 335:959-962.

Thorne, A., R. Grün, G. Mortimer, N. A. Spooner, J. J. Simpson, M. McCulloch, L. Taylor, and D. Curnoe. 1999. Australia's oldest human remains: age of the Lake Mungo 3 skeleton. Journal of Human Evolution 36:591-612.
Tieszen, L. L. 1991. Natural variations in the carbon isotope values of plants: implications for archaeology, ecology, and paleoecology. Journal of the Archaeological Sciences 18:227-248.

Triggs, B. 2009. Wombats, 2nd ed. Victoria, Australia: CSIRO Publishing.

Trueman, C. N. G., J. H. Field, J. Dortch, B. Charles, and S. Wroe. 2005. Prolonged coexistence of humans and megafauna in Pleistocene Australia. Proceedings of the National Academy of Sciences USA 102:8381-8385.

Turney, C. S. M., M. I. Bird, L. K. Fifield, R. G. Roberts, M. Smith, C. E. Dortch, R. Grun, E. Lawson, L. K. Ayliffe, G. H. Miller, J. Dortch, and R. G. Cresswell. 2001. Early human occupation at Devil's Lair, southwestern Australia 50,000 years ago. Quaternary Research 55:3-13.

Turney, C. S., T. F. Flannery, R. G. Roberts, C. Reid, L.K. Fifield, T. F. Higham, Z. Jacobs, N. Kemp, E. A. Colhoun, R. M. Kalin, and N. Ogle. 2008. Late-surviving megafauna in Tasmania, Australia, implicate human involvement in their extinction. Proceedings of the National Academy of Sciences USA 105:12150-12153.

Ungar, P. S., C. A. Brown, T. S. Bergstrom, and A. Walker. 2003. Quantification of dental microwear by tandem scanning confocal microscopy and scale-sensitive fractal analyses. Scanning 25: 185-193.

Ungar, P. S., G. Merceron, and R. S. Scott. 2007. Dental microwear texture analysis of Varswater bovids and early Pliocene paleoenvironments of Langebaanweg, Western Cape Province, South Africa. Journal of Mammalian Evolution 14:163-181.

van der Merwe, N. J., and E. Medina. 1989. Photosynthesis and ${ }^{13} \mathrm{C} /{ }^{12} \mathrm{C}$ ratios in Amazonian rain forests. Geochimica et Cosmochimica Acta 53:1091-1094.

Williams, A. N. 2013. A new population curve for prehistoric Australia. Proceedings of the Royal Society of London B 280:20130486.

Wroe, S., and J. H. Field. 2006. A review of the evidence for a human role in the extinction of Australian megafauna and an alternative interpretation. Quaternary Science Reviews 25:2692-2703.

Wroe, S., J. Field, R. Fullagar, and L. S. Jermin. 2004. Megafaunal extinction in the late Quaternary and the global overkill hypothesis. Alcheringa 28:291-331.

Wroe, S., J. H. Field, M. Archer, D. K. Grayson, G. J. Price, J. Louys, J. T. Faith, G. E. Webb, I. Davidson, and S. D. Mooney. 2013 Climate change frames debate over the extinction of megafauna in Sahul (Pleistocene Australia-New Guinea). Proceedings of the National Academy of Sciences USA 110:8777-8781. 